\title{
Efeitos do microcrédito rural sobre a produção agropecuária na região Nordeste: evidências do Programa Agroamigo
}

\author{
Effects of rural microcredit on agricultural production: evidence from the \\ Agroamigo program
}

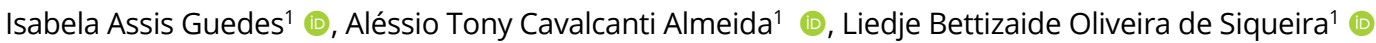 \\ ${ }^{1}$ Programa de Pós-Graduação em Economia do Setor Público (PPESP), Universidade Federal da Paraíba (UFPB), João Pessoa \\ (PB), Brasil. E-mails: isabela.aguedes@gmail.com; alessio@lema.ufpb.br; liedjesiqueira@gmail.com
}

Como citar: Guedes, I. A., Almeida, A. T. C., \& Siqueira, L. B. O. (2021). Efeitos do microcrédito rural sobre a produção agropecuária na região Nordeste: evidências do Programa Agroamigo. Revista de Economia e Sociologia Rural, 59(1), e210774. https://doi.org/10.1590/1806-9479.2021.210774

Resumo: O presente trabalho objetiva avaliar o efeito do microcrédito rural sobre o valor da produção agropecuária dos municípios nordestinos atendidos pelo Programa Agroamigo, levando em consideração o volume concedido de empréstimos e o tempo de exposição aos beneficiários. Para tanto, utilizou-se do modelo de diferenças em diferenças (DD) com controle para efeito fixo para um painel anual de 1.791 municípios da região entre 2003 e 2015, usando dados administrativos do programa, indicadores sociais da Relação Anual de Informações Sociais (RAIS), dados pluviométricos do Centre for Environmental Data Analysis (CEDA) e indicadores demográficos, econômicos e de produção agropecuária do Instituto Brasileiro de Geografia e Estatística (IBGE). Os principais resultados da pesquisa mostram que o volume de empréstimos do Agroamigo produziu um efeito positivo sobre a produção pecuária, potencializado para aqueles municípios com mais de sete anos de exposição ao programa. Contudo, não se encontraram efeitos significativos estatisticamente na atividade agrícola. Por fim, ao confrontar os valores totais concedidos de microcrédito e os benefícios gerados, medidos apenas em termos da produção pecuária, constata-se que o programa apresentou uma taxa de retorno de 52\% no agregado de 2005 a 2015.

Palavras-chave: avaliação de impacto, microcrédito rural, Agroamigo, produção agropecuária, nordeste.

\begin{abstract}
This study aims to evaluate the effect of rural microcredit on the value of agricultural production in the Northeastern Brazilian municipalities served by the Agroamigo Program, considering the amount of loans granted and the time of exposure to benefits. Therefore, it was used the differences in differences (DD) method with control for fixed effect for an annual panel of 1,791 municipalities in the region from 2003 to 2015, using administrative data from the Program, social indicators of the Annual Report of Social Information (RAIS), rainfall data from the Centre for Environmental Data Analysis (CEDA), and demographic, economic and agricultural production indicators of the Brazilian Institute of Geography and Statistics (IBGE). The main results of the research show that Agroamigo's loan volume had a positive effect on livestock production, and this effect was potentiated for those municipalities with more than seven years of exposure to the Program. However, no statistically significant effects were found on agricultural activity. Finally, compared to the total amounts of microcredit and the benefits generated, measured only in terms of livestock production, it was identified that the program presented a return rate of 52\% the aggregate from 2005 to 2015.
\end{abstract}

Keywords: impact evaluation, rural microcredit, Agroamigo, agricultural production, northeast. 


\section{Introdução}

Nas últimas três décadas, governos do mundo todo têm implementado ações para reduzir a pobreza e ajudar as famílias a sair da pobreza extrema. Nesse sentido, o microcrédito tem sido apontado por pesquisadores e formuladores de políticas públicas como importante ferramenta de desenvolvimento social e econômico (Banerjee \& Duflo, 2011; Chen \& Snodgrass, 2001; Koloma \& Aila, 2014; Goldberg, 2005; Hermes \& Lensink, 2007; Pitt \& Khandker, 1998).

Segundo Reed (2015), o microcrédito apresenta números expressivos em escala global em termos de atendimento e concessão de crédito. Em 1997, dos 13 milhões de beneficiados, 8 milhões eram pobres ou viviam abaixo da linha da pobreza. Em 2013, o microcrédito beneficiou 211 milhões de clientes, dos quais 114 milhões viviam na pobreza extrema. Molineus (2015) aponta que, ao longo das últimas duas décadas, o microcrédito movimentou um volume de recursos entre $\$ 60$ e $\$ 100$ bilhões, possuindo cerca de 200 milhões de clientes, e com perspectiva de crescimento para os próximos anos.

Dados do Banco Mundial (2008) apontam que, nos países em desenvolvimento, 75\% das pessoas de baixa renda vivem em áreas rurais e que a maioria depende direta ou indiretamente da agricultura para sua subsistência. Cerca de $86 \%$ da população rural do mundo (2,5 bilhões de pessoas) depende da agricultura, e esta, por sua vez, gera emprego para 1,3 bilhão de pequenos produtores e trabalhadores sem-terra. Dessa forma, de acordo com essa instituição, em pleno século XXI, a produção agrícola ainda desempenha um papel fundamental no mundo para o desenvolvimento sustentável e a redução da pobreza e fome; portanto, a concessão do microcrédito aos pequenos produtores rurais também se apresenta como mecanismo da política pública de promover o fortalecimento da agricultura.

Diversos estudos na literatura internacional têm buscado mostrar a influência do microcrédito na produção agrícola de pequeno porte, tais como: Alam (1988), Akwaa-Sekyi (2013), Ashaolu et al. (2011), Dong et al. (2010), Feder et al. (1990), Guirkinger \& Boucher (2007), Lowder et al. (2014), Shah et al. (2015), Sharmeen \& Chowdhury (2013), Sulemana \& Adjei (2015). Não obstante, existem trabalhos que mostram a ausência de impactos do microcrédito na produtividade e indicadores de pobreza, como os de Banerjee et al. (2015b), Bateman \& Chang (2012), Coleman (2006), Feder et al. (1990), Guirkinger \& Boucher (2007), Hulme \& Mosle (1996) e Morduch (1998).

No Brasil, as primeiras experiências relacionadas ao microcrédito remontam à década de 1970 e, em anos mais recentes, estão sendo orientadas pela Lei $n^{\circ} 11.110 / 2011$, que estabeleceu o Programa Nacional de Microcrédito Produtivo Orientado (PNMPO), voltado para incentivar as atividades produtivas de pequeno porte, estimulando emprego e renda desse setor. Para o setor agrícola especificamente, o governo federal criou, a partir de 1996, o Programa Nacional de Fortalecimento da Agricultura Familiar (Pronaf), que visa fornecer crédito de custeio e investimento aos agricultores familiares de forma mais acessível e com menor custo do que os praticados no mercado. Este programa vem sendo reestruturado ao longo dos anos e, na sua versão atual, é definido para atender a quatro grupos de beneficiários (A, B, C e D), que possuem regras específicas para obtenção de créditos. Exceto o grupo A, destinado para as famílias assentadas pelo Programa de Crédito Especial para Reforma Agrária, para as demais categorias há um critério de renda anual familiar que determina o valor do empréstimo a ser obtido e as condições diferenciadas de pagamento (Maia \& Pinto, 2015).

Desta forma, estabeleceu-se o Pronaf B, voltado para um público-alvo com renda bruta familiar anual de até $R \$ 20$ mil, excetuando os ganhos obtidos com as aposentadorias rurais. Os valores máximos de empréstimos para esse grupo é de até $R \$ 4$ mil, com condições bastante favoráveis de juros e bônus de adimplência. Embora seja um grupo que tenha benefícios, havia sérios problemas de inadimplência e má destinação dos recursos, com os desvios destes para pagamento de despesas de consumo. Para dirimir esses problemas, o Banco do Nordeste do Brasil (BNB) estabeleceu o Programa Agroamigo, que se apresenta como uma nova metodologia de orientação e acompanhamento dos financiamentos realizada especificamente para os tomadores de empréstimos que se enquadram dentro da linha de financiamento do Pronaf B (Banco do Nordeste, 2016). 
Estudos na literatura nacional, como os de Abramovay et al. (2013), Batista \& Neder (2014), Gazolla \& Schneider (2013), Pereira \& Nascimento (2014) e Silva \& Alves Filho (2009), veem o microcrédito rural como um importante mecanismo de acesso ao mercado de crédito para as camadas mais vulneráreis da população. Contudo, os estudos ainda não são consensuais sobre o efeito final que o microcrédito rural pode desempenhar sobre a pobreza e a renda dos pequenos produtores. Aquino \& Bastos (2015) mostram que esse programa ainda apresenta algumas fragilidades em sua realização, por exemplo, concentração de empréstimos para área pecuária, alta inadimplência e falta de políticas públicas estruturantes para dar suporte ao pequeno produtor.

Nesse contexto, o presente estudo, através do modelo de diferenças em diferenças (DD), ou diff-in-diff, com efeitos fixos, analisa o papel do microcrédito rural sobre o valor da produção agropecuária nos municípios nordestinos atendidos pelo Programa Agroamigo. Testa-se a hipótese de que os municípios que recebem mais recursos ${ }^{1}$ e que estão expostos ao programa por mais tempo ${ }^{2}$ conseguem apresentar melhores resultados na produção agropecuária.

A importância deste estudo é avaliar os efeitos de um programa que já movimentou, entre 2005 a 2015, o valor superior a R $\$ 8$ bilhões (Banco do Nordeste, 2016). Portanto, é uma atividade com elevados custos para os cofres públicos, e o acompanhamento do retorno desse programa para sociedade deve ser averiguado tanto nos aspectos econômicos como sociais. O estudo centra-se na questão econômica e nos seus desdobramentos sobre o valor da produção agropecuária nos municípios. A contribuição específica para a literatura é usar dados em painel para os municípios, com detalhamento sobre o programa provido pelo BNB, buscando observar os seus efeitos agregados em uma perspectiva da produção agropecuária, usando para tanto uma estratégia de avaliação quase experimental, com controle para heterogeneidade observada e não observada invariante no tempo.

Seguida desta parte introdutória, a segunda seção faz uma revisão da literatura. A terceira seção traz uma breve descrição do Programa Agroamigo e apresenta dados sobre a sua cobertura nos municípios. A quarta seção contém informações metodológicas com citação da fonte dos dados e apresentação da estratégia empírica necessária ao desenvolvimento do trabalho. A quinta seção apresenta os resultados encontrados, e, por último, a sexta seção faz as considerações finais.

\section{Revisão da literatura}

O grande marco histórico que serviu de modelo para difundir o microcrédito ocorreu em Bangladesh, na década de 1970, de uma experiência iniciada pelo economista Muhammad Yunus, fundador do Grameen Bank e ganhador do Prêmio Nobel da Paz em 2006. A ideia defendida abertamente por Yunus (2001) é de que o microcrédito é um programa de mudança social, que permite aos mais pobres exercerem suas habilidades e capacidade de produzir.

De acordo com Osmani \& Mahmud (2015) e Quayes \& Khalily (2014), o microcrédito é a concessão de empréstimos de baixo valor a indivíduos e pequenos empreendedores informais que não possuem acesso formal ao sistema financeiro tradicional, diferenciando-se dos demais tipos de empréstimo primordialmente em função da metodologia utilizada. Para Abramovay et al. (2013) e Yunus \& Jolis (2000), o microcrédito assume-se como um instrumento de combate à pobreza e melhora das condições de vida dos indivíduos.

Goldberg (2005) afirma que grande parte dos estudos iniciais sobre impacto do microcrédito apresenta resultado positivo na pobreza e renda dos seus beneficiários.

Um dos primeiros estudos abrangentes de impacto foi realizado por Hossain (1988, p. 10), apontando que "a renda familiar média dos tomadores de microcrédito junto ao Grameen era $43 \%$ superior à dos não tomadores de microcrédito, sendo as maiores diferenças no estrato de menor renda".

\footnotetext{
${ }^{1}$ Contabilizados a partir da soma dos empréstimos individuais fornecidos dentro do Programa Agroamigo.

${ }^{2} \mathrm{O}$ tempo de exposição do município é contado pela quantidade de anos em que o município apresentou pelo menos um contrato de adesão de algum produtor local ao Programa Agroamigo.
} 
Trabalhos como os de McKernan (2002) e Pitt \& Khandker (1998) demonstraram que, embora o efeito seja positivo, a magnitude do impacto do microcrédito na oferta de trabalho, as despesas, os bens adquiridos, a escolaridade das crianças, a fertilidade, o uso de contraceptivos e os lucros do trabalho dependem do sexo do participante do programa de crédito. Hermes \& Lensink (2007) e Khandker (2005) também realizaram estudos sobre o microcrédito e elencaram os efeitos positivos dessa política, entre os quais o aumento da renda familiar e dos bens das mulheres, a melhoria da escolaridade dos filhos, a superação da linha da pobreza e o desenvolvimento local.

O microcrédito sob a perspectiva da responsabilidade conjunta e da atuação de grupos solidários foi analisado nos trabalhos de Karlan (2007) e Wenner (1995), cujos resultados indicaram que o desempenho do reembolso de grupos solidários melhora quando estes possuem regras formais de como seus membros devem se comportar.

Os estudos de Hulme \& Mosle (1996) apontaram que o crescimento da renda familiar dos tomadores de microcrédito sempre se apresentava superior ao crescimento de renda das famílias não tomadoras de crédito, corroborando os resultados das pesquisas iniciais de Hossain. Pesquisas realizadas por Agbola et al. (2017), Banerjee \& Duflo (2011) e MkNelly \& Dunford $(1998,1999)$ indicaram que, além do aumento de renda familiar, o microcrédito proporciona a melhoria do bem-estar econômico por meio da estabilização do consumo, da melhoria das condições de moradia e da propriedade de bens.

Sob a perspectiva da intervenção do microcrédito na produção agrícola, diversos trabalhos foram realizados apresentando diferentes enfoques. Alam (1988) investigou o crescimento da produtividade dos agricultores com acesso ao microcrédito pelo Grameen Bank, constatando que pequenos agricultores poderiam melhorar sua produtividade alocando parte de suas terras para o cultivo de variedades de alto rendimento. Ashaolu et al. (2011) realizaram um estudo na Nigéria e concluíram que o aumento no nível de produção agrícola nesse país ocorreu por causa do fortalecimento financeiro dos agricultores por meio do acesso ao microcrédito. Akwaa-Sekyi (2013) afirma que o microcrédito contribui para o desenvolvimento agrícola, especificamente na mão de obra empregada, capital de giro, produção e renda dos agricultores.

Estudo realizado por Shah et al. (2015) na cidade de Mastung, no Paquistão, concluiu que o microcrédito fornece apoio financeiro aos agricultores, contribuindo para o desenvolvimento do setor agrícola, o aumento da produção agrícola e, consequentemente, a elevação da renda. Trabalho realizado por Sulemana \& Adjei (2015) em Gana verificou que o acesso ao microcrédito permitiu aos agricultores a adoção de técnicas agrícolas mais modernas e uso de sementes de alta produção, impactando positivamente nos níveis de produção. De forma semelhante, Zeller et al. (1998) concluíram que a participação em um programa de crédito agrícola possibilita o acesso a melhores tecnologias agrícolas e de maior rentabilidade, elevando a produção do milho e tabaco híbridos no Malawi.

Sharmeen \& Chowdhury (2013) afirmam que parte do microcrédito é destinado aos agricultores pobres para compra de insumos como sementes, irrigação e fertilizantes, além de terem encontrado uma correlação positiva entre o microcrédito agrícola e o aumento da produção em Bangladesh.

Embora o microcrédito seja tradicionalmente considerado como uma política de desenvolvimento econômico e social local, fundamental para a superação da pobreza, a geração de trabalho e renda e o fomento da produção agropecuária, ainda não existe um consenso no que se refere ao seu efeito na literatura e nas pesquisas internacionais de impacto. Isso porque, no final da década de 1990, diversos estudos passaram a criticar os resultados alcançados pelo microcrédito.

Morduch (1998) questionou a validade e o rigor dos estudos realizados sobre o microcrédito em Bangladesh, afirmando não existir evidência estatística que comprovasse o aumento no consumo entre os indivíduos que realizavam empréstimo por meio do microcrédito em relação aos que o não realizavam. De acordo com Bateman \& Chang (2012), os efeitos positivos do microcrédito são de curto prazo e apenas para alguns indivíduos "sortudos". Além disso, constitui-se em uma poderosa barreira institucional e política para o desenvolvimento econômico e social sustentável e também para a redução da pobreza. Coleman (2006), com base em estudo de impacto realizado na Tailândia, concluiu que havia 
um viés nos resultados do microcrédito e que não era possível atribuir unicamente a este a solução para retirar as pessoas da pobreza.

Autores como Hulme \& Mosle (1996) e Banerjee et al. (2015a) afirmam nos seus estudos que não encontraram efeitos significativos do microcrédito no consumo das famílias, na educação, na saúde ou no empoderamento das mulheres. Banerjee et al. (2015b) compilaram os resultados de seis estudos aleatórios realizados sobre o microcrédito nas áreas urbanas e rurais da Bósnia, Etiópia, Índia, México, Marrocos e Mongólia, mostrando que nenhum deles encontrou impacto significativo na renda familiar dos beneficiários.

Feder et al. (1990) afirmam que parte do crédito concedido aos produtores é desviada para o consumo, fazendo com que o efeito provável da produção seja menor do que o esperado. Guirkinger \& Boucher (2007) apontaram que as restrições de crédito afetam negativamente a alocação de recursos, prejudicando a produção agrícola dos pequenos agricultores peruanos. Conclusão semelhante encontra-se no estudo realizado por Dong et al. (2010) na China. Para Armendariz \& Morduch (2005), ainda existe uma série de questionamentos sobre o efeito do microcrédito que não foi amplamente pesquisada e explicada.

Para o Programa Agroamigo, objeto de estudo nesta pesquisa, encontra-se um número razoável de estudos na literatura. No ano de 2015, o BNB lançou uma coletânea de artigos que traz uma avaliação do programa após 10 anos do seu funcionamento. Em uma avaliação global do programa, destacam-se os trabalhos de Aquino \& Bastos (2015) e Maia \& Pinto (2015), os quais enfatizaram a importância do papel do Programa Agroamigo para o bom o desempenho do Pronaf B. Oliveira et al. (2015) analisaram o grau de concentração e nível de aderência dos recursos da carteira de financiamento do programa, enquanto Baiardi et al. (2015) investigaram a percepção dos beneficiários do programa. Fora estes, importantes contribuições quanto ao efeito econômico da participação do programa na vida dos agricultores podem ser vistas em Neri (2012) e Abramovay et al. (2013).

\section{Uma breve descrição do Programa Agroamigo e a sua cobertura nos municípios}

O Agroamigo é o nome dado ao programa de microcrédito rural do Banco do Nordeste criado em 2005 e voltado para atender ao público da linha de financiamento rural do Pronaf $B$ dentro da sua área de atuação. Todos os empréstimos do Pronaf B no BNB se enquadram nesse programa, o qual se apresenta com uma metodologia inovadora por possuir uma forma diferenciada de acompanhamento dos produtores por meio de assessores de microcréditos. Esses agentes passaram a ser responsáveis pela divulgação do programa no campo, pela orientação ao processo de formalização simplificada do pedido do crédito ao banco e, por fim, pelo acompanhamento do pagamento do empréstimo. O Programa Agroamigo ficou conhecido, portanto, por adotar uma metodologia de microcrédito produtivo orientado e centrado na figura do assessor do crédito (Banco do Nordeste, 2016).

A principal fonte de recursos para realização dos empréstimos vem do Fundo Constitucional de Financiamento do Nordeste (FNE), embora haja outras fontes de recursos como os provenientes do Fundo de Amparo ao Trabalhador (FAT), da poupança rural, do orçamento geral da União, das exigibilidades bancárias, dentre outros (Conti \& Roitman, 2011).

A criação da metodologia de microcrédito rural foi influenciada pelo sucesso da experiência do microcrédito urbano do próprio Banco do Nordeste com o Programa Crediamigo, que inspirou uma ação similar apropriada nas comunidades rurais. São objetivos do programa aumentar a renda familiar, criar empregos no meio rural, aumentar a oferta de alimentos para a população do campo e das cidades e melhorar a qualidade de vida da população rural (Matos et al., 2014).

O programa possui como público-alvo agricultores familiares que se enquadram no Pronaf, classificados basicamente de acordo com o rendimento bruto anual e o valor do financiamento: Agroamigo Crescer, financiamentos de até $\mathrm{R} \$ 4$ mil e renda bruta anual de até $\mathrm{R} \$ 20$ mil; Agroamigo Mais, para montantes de até $\mathrm{R} \$ 15$ mil para agricultores familiares que obtenham renda bruta anual de até $\mathrm{R} \$ 360$ mil e se enquadrem no Pronaf V (renda variável). Nesses grupos atendidos pelo Agroamigo, incluem-se todos os que exploram parcela de terra, 
tanto na condição de proprietário, posseiro e arrendatário quanto na condição de parceiro; que residem na propriedade rural ou em local próximo; e obtêm no mínimo 50\% da renda familiar da exploração do estabelecimento rural. ${ }^{3}$ (Neri, 2012).

Para entender a importância desses programas de microcréditos, é necessário dimensionar a importância da agricultura familiar para o país. O Censo Agropecuário de 2006 identificou que, do total de estabelecimentos agropecuários no Brasil, 4.367 .902 eram de agricultores familiares, representando $84,4 \%$ dos estabelecimentos brasileiros, dos quais a metade deles estava no Nordeste (França et al., 2009).

Ainda utilizando esse Censo como base, Guilhoto et al. (2007) afirmam que o segmento familiar da agropecuária brasileira e as cadeias produtivas a ela interligadas responderam, em 2005, por 9\% do PIB brasileiro. Considerando que o agronegócio nacional foi responsável por 27,9\% do PIB no referido ano, fica evidente a importância da agricultura familiar na geração de riqueza do país. Guanziroli (2007) e Aquino \& Teixeira (2005) ressaltam que para haver um desempenho econômico viável dessa atividade, é necessária a implementação de assistência técnica e políticas públicas adequadas. Assim, o microcrédito tem se destacado como uma ferramenta de fomento da agricultura familiar, haja vista a dificuldade na aquisição de crédito formal ser frequentemente argumentada como uma das restrições à expansão da capacidade produtiva dos pequenos agricultores.

O Agroamigo surgiu, assim, como forma de fortalecer esse segmento da agricultura. O programa iniciou-se no ano de 2005, abrangendo 259 dos 1.794 municípios nordestinos. A sua evolução é retratada na Figura 1. Percebe-se que a ampliação do programa ocorreu de forma rápida, apresentando uma cobertura de mais de $50 \%$ dos municípios ${ }^{4}$ em apenas três anos e atingindo mais de 98\% dos municípios em 2015.

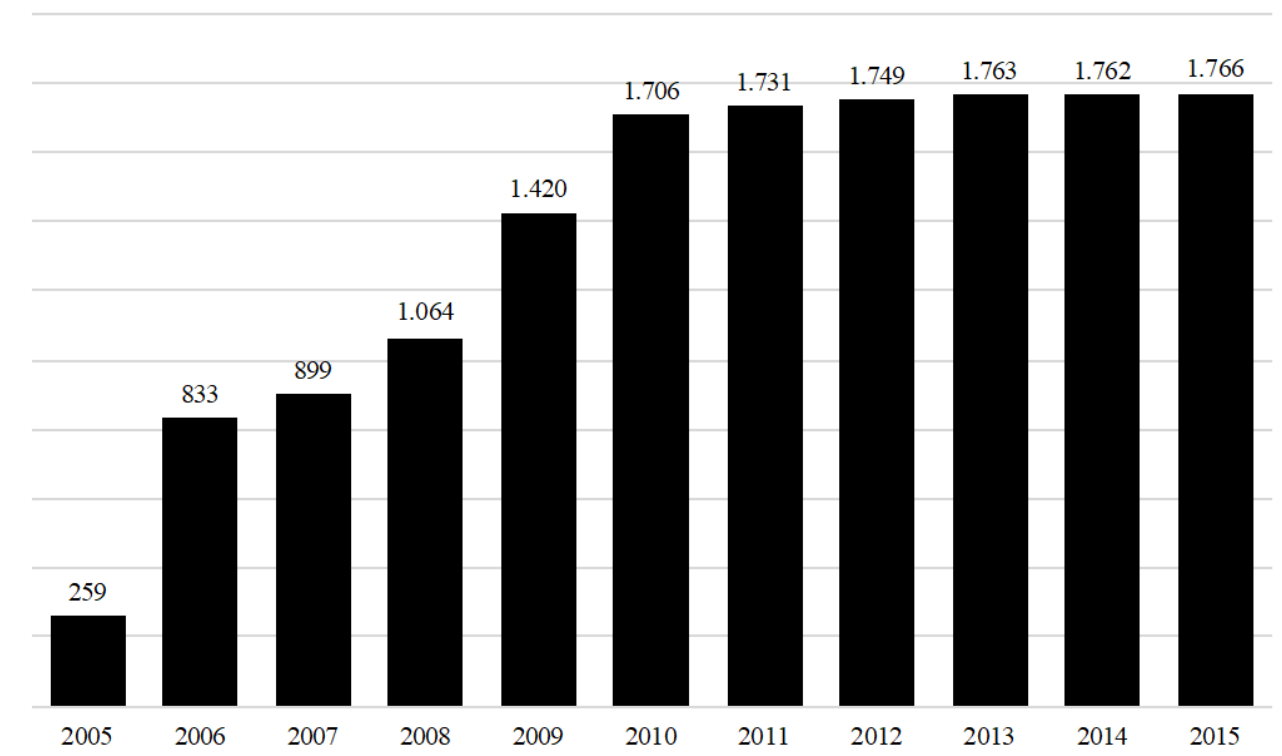

Figura 1 - Evolução da cobertura do Programa Agroamigo em termos da quantidade de municípios atendidos por ano, de 2005 a 2015.

Fonte: elaborada pelos autores a partir dos microdados do Programa Agroamigo, de 2005 a 2015.

Um avanço expressivo também é verificado em termos operacionais. O volume de recursos destinados ao Agroamigo e a quantidade de operações de crédito realizada acompanhou a evolução do programa. Na Figura 2, observa-se que os números iniciais foram

\footnotetext{
3 Os agricultores clientes do Agroamigo podem desenvolver qualquer atividade, seja agrícola, pecuária ou não agropecuária no meio rural, que gere renda no campo ou nas proximidades urbanas como agroindústria, pesca, turismo rural, serviços no meio rural e artesanato.

${ }^{4}$ Os municípios são considerados cobertos pelo programa em determinado ano quando houver pelo menos um produtor cliente do Agroamigo.
} 
bastantes modestos, apresentando um crescimento gradativo ao longo dos anos. De acordo com os dados da pesquisa, de 2005 a 2015, o Agroamigo contratou mais de 2,8 milhões de operações de crédito, atingindo um volume de contratação superior a $\mathrm{R} \$ 8$ bilhões ao longo dos seus 11 anos iniciais.

Também houve um aumento no volume de recursos contratados e operações executadas principalmente a partir de 2012. Esse comportamento pode ser explicado pelas alterações dos limites de concessão de crédito ocorridas ao longo do programa, bem como por sua ampliação, em 2012, com a criação do Agroamigo Mais.

Desagregando os dados para uma análise individual dos empréstimos concedidos dentro do Agroamigo, constata-se que $43 \%$ das operações contratadas ao longo do programa foram realizadas por mulheres, atingindo um dos objetivos de promover a inserção produtiva desse grupo. Um outro fato importante observado é que $74 \%$ dos recursos foram aplicados na pecuária, com agricultura recebendo $24 \%$ e as demais atividades sendo responsáveis por $2 \%$. Na pecuária, os recursos também são concentrados na bovinocultura, com $42,32 \%$ do total de financiamentos concedidos pelo Agroamigo, seguida pela suinocultura, avicultura e ovinocultura, com $12,24 \%, 11,15 \%$ e $10,6 \%$, respectivamente.

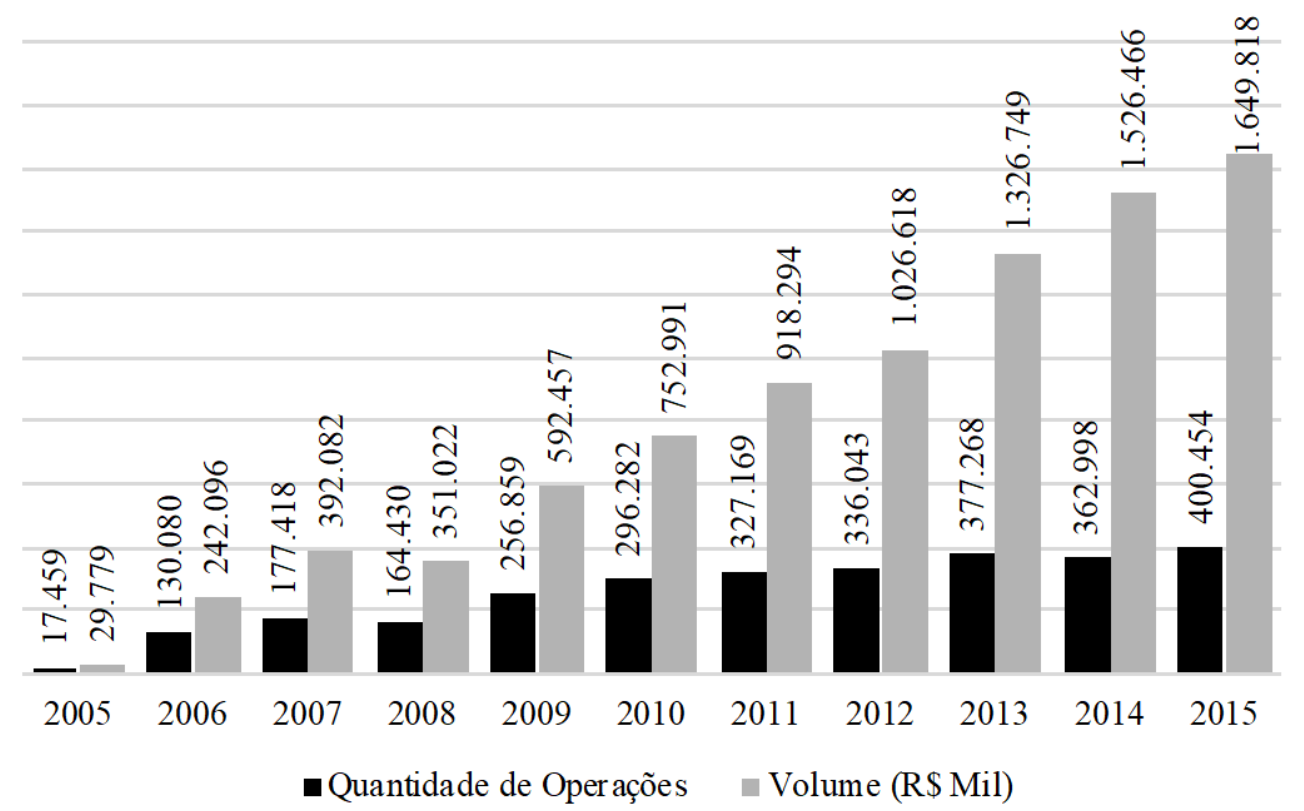

Figura 2 - Quantidade de operações de crédito e valores contratados (em R\$ mil) por ano, de 2005 a 2015. Fonte: elaborada pelos autores a partir dos microdados do Programa Agroamigo, de 2005 a 2015. Nota: valores corrigidos monetariamente pelo Índice Nacional de Preços ao Consumidor Amplo (IPCA), tendo 2015 como período de referência.

\section{Aspectos metodológicos}

\subsection{Dados e variáveis}

Para a execução deste trabalho, utilizou-se das bases de dados do Banco do Nordeste do Brasil (BNB), da Relação Anual de Informações Sociais (RAIS) do Ministério do Trabalho e Emprego (MTE) e do Instituto Brasileiro de Geografia e Estatística (IBGE), que possibilitaram a construção de um painel anual de 1.791 municípios para o período de 2003 a 2015, incluindo dois períodos pré-programa (2003 e 2004). Os dados do Agroamigo, disponibilizados pelo BNB, contêm informações sobre os municípios e estados que possuem agricultores familiares beneficiados ${ }^{5}$, a quantidade (número de contratações) e o valor das contratações realizadas,

\footnotetext{
${ }^{5}$ Foram utilizados os dados da região Nordeste, por representar $87 \%$ da área de cobertura do BNB e $91 \%$ da carteira ativa do Agroamigo.
} 
os setores e atividades financiados pelo programa, bem como a distribuição das atividades por gênero. O painel construído a partir desses dados possibilita identificar o número de municípios que começou a participar do programa no ano de 2005, por meio dos empréstimos concedidos aos seus agricultores familiares, e o volume de recursos contratados, permitindo verificar a intensidade de cobertura e o tempo de exposição dos municípios ao Agroamigo.

Os valores da produção agrícola e pecuária foram obtidos a partir das pesquisas da Produção Agrícola Municipal (PAM) e da Produção da Pecuária Municipal (PPM) do IBGE. Nessas bases, há informações sobre culturas permanentes e temporárias, produção de efetivos das espécies animais criadas e subprodutos por eles gerados, tais como produções de leite, lã, ovos de galinhas e de codornas, mel e casulos de bicho-da-seda. As variáveis de controle utilizadas na pesquisa foram escolhidas em função da disponibilidade dos dados para os municípios e usadas para tentar controlar alguma mudança ocorrida nos municípios ao longo do tempo que pudessem estar relacionadas com as variáveis de desfecho e com a variável indicadora de tratamento. As variáveis de controle foram formadas pela população rural ${ }^{6}$, potencial de mercado (capturado pela massa salarial), diversificação da capacidade de produção local, nível de educação e condições climáticas.

A Tabela 1 apresenta a descrição das variáveis utilizadas no presente trabalho, bem como as suas respectivas fontes.

Tabela 1 - Descrição das variáveis utilizadas nos modelos de regressão.

\begin{tabular}{|c|c|c|}
\hline Variável & Descrição & Fonte \\
\hline \multicolumn{3}{|c|}{ Indicadores de impacto } \\
\hline & Valor total da produção agropecuária (em mil reais) & PPM e PAM \\
\hline & Valor total da produção agrícola (em mil reais) & PAM \\
\hline & Valor total da produção pecuária (em mil reais) & PPM \\
\hline \multicolumn{3}{|c|}{ Cobertura do programa } \\
\hline TEMPO & $\begin{array}{l}\text { Tempo de exposição do município ao Programa } \\
\text { Agroamigo (em anos) }\end{array}$ & Agroamigo* \\
\hline VAGRO & $\begin{array}{l}\text { Valor de recursos total repassados pelo Programa } \\
\text { Agroamigo (em mil reais) }\end{array}$ & Agroamigo* \\
\hline \multicolumn{3}{|l|}{ Variáveis de controle } \\
\hline POPRURAL & Estimativas da população rural & IBGE \\
\hline PORTE & $\begin{array}{l}\text { Variável categórica com seis níveis de população } \\
\text { total (até } 5 \text { mil, de } 5 \text { a } 10 \text { mil, de } 10 \text { a } 20 \text { mil, de } \\
20 \text { a } 50 \text { mil, de } 50 \text { a } 100 \text { mil e acima de } 100 \text { mil) }\end{array}$ & IBGE \\
\hline MASSA SALARIAL & $\begin{array}{l}\text { Soma do total dos rendimentos do trabalho } \\
\text { formal (em milhões reais) }\end{array}$ & MTE \\
\hline TRABALHADORES & Número total de vínculos ativos formais & MTE \\
\hline FACULDADES & $\begin{array}{l}\text { Número de faculdades (ensino superior) por } \\
\qquad 100 \text { mil habitantes }\end{array}$ & MTE e IBGE \\
\hline IB-A & Índice de diversificação da produção agrícola & IBGE \\
\hline IB-P & Índice de diversificação da produção pecuária & IBGE \\
\hline DESVPREC & $\begin{array}{l}\text { Porcentagem de desvio do volume de } \\
\text { precipitação em relação à média histórica }\end{array}$ & CEDA \\
\hline
\end{tabular}

Fonte: elaborada pelos autores. * Dados administrativos do Programa Agroamigo. Nota: as informações financeiras foram corrigidas monetariamente pelo Índice Nacional de Preços ao Consumidor Amplo (IPCA), tendo 2015 como período de referência.

\footnotetext{
${ }^{6}$ A projeção da população rural foi calculada com base na taxa de população rural em 2010 do IBGE e nas estimativas populacionais anuais.
} 
A massa salarial representa o somatório de todos os salários pagos aos trabalhadores formais no município em um dado período de tempo. Essa variável está ligada à oferta e demanda, pois se espera que um aumento na massa salarial possa aumentar o consumo de produtos agrícolas, incentivando a produção na região. Por sua vez, a diversificação da produção foi medida pelo índice de Berry, também conhecido como índice de Simpson, que assume o valor 0 quando existem monoculturas e se aproxima de 1 quando a diversificação da produção é total. Essa variável foi utilizada no modelo por que, para os pequenos produtores, diversificar a produção proporciona importantes benefícios, principalmente no que se refere à conservação ambiental, segurança da renda e segurança alimentar (Baumgartner \& Quaas, 2010; Lin, 2011).

A variável educação foi incluída, pois se espera que um maior nível de escolaridade da população local impacte positivamente na produção. De acordo com Menezes et al. (2014), ainda que a agropecuária amargue a posição de atividade econômica com menor produtividade e menos anos de estudo por trabalhador, esse setor teve um dos maiores crescimentos relativos no nível educacional dos trabalhadores entre 1996 e 2009.

Por fim, incluiu-se uma variável relacionada às condições climáticas, haja vista a importância desse fator para as atividades agropecuárias. Dessa forma, a última especificação do modelo de avaliação de impacto apresentada na seção de resultados acrescenta o desvio das chuvas nos últimos 12 meses no i-ésimo município para cada ano do painel. Essa variável é calculada por: DesvPrec $_{i t}=\left[\ln \left(p_{i t}\right)-\ln \left(\bar{p}_{i}\right)\right] \times 100$, sendo interpretada como uma porcentagem de desvio do volume de precipitação $\left(p_{i t}\right)$ no município $i$ no ano $t$ em relação à sua média histórica $\left(\bar{p}_{i}\right)$ de 1986 a 2016. Os dados climáticos são oriundos do Centre for Environmental Data Analysis (CEDA), que possui séries históricas de variações mensais de precipitações ao redor do mundo a partir de análises de satélites, sensores e outros dados espaciais (CEDA Archive, 2019).

\subsection{Estratégia empírica}

A estratégia empírica consiste em avaliar o efeito do Agroamigo sobre o valor da produção agropecuária dos municípios nordestinos por meio de um painel anual entre os anos de 2003 e 2015. Para consecução deste trabalho, utilizou-se do método DD, com controle para heterogeneidade observada e não observada invariante no tempo. A estratégia de identificação se baseia em Galiani et al. (2005), a qual, considerando um escalonamento na cobertura do programa entre os municípios, usa o tempo de exposição para avaliar os efeitos da intervenção. Com base na importância da intensidade da cobertura do programa, o valor total de empréstimos concedidos foi usado para mensurar o impacto.

Ademais, a variável de impacto escolhida para análise foi o valor da produção agropecuária, cuja análise realizada foi feita considerando o efeito total e específico (pecuária e agricultura). Este trabalho parte da premissa de que o Agroamigo exerce um efeito positivo na produção agropecuária dos municípios que recebem um maior volume de recursos (por intermédio dos empréstimos concedidos aos clientes) e com maior quantidade de anos de exposição. Com essas considerações, a especificação empírica é dada pela Equação 1:

$Y_{i t}=\beta_{0}+\sum_{j=1}^{J} \beta_{1 j} T E M P O_{j, i t}+\beta_{2} V A G R O_{i t}+\vec{\gamma} \vec{W}_{i t}+a_{i}+\delta_{t}+\epsilon_{i t}$,

em que $Y_{i t}$ representa o valor da produção agropecuária para o município $i$ no ano $t$; TEMPO $_{j, i t}$ é uma variável binária que assume valor 1 caso o município $i$ no ano $t$ tenha sido beneficiado por $j$ anos pelo Agroamigo; $V A G R O_{i t}$ representa o valor total repassado pelo programa; $\vec{W}_{i t}$ é um vetor composto de variáveis de controle observáveis variantes no tempo; $a_{i}$ é o efeito fixo dos municípios; $\delta_{t}$ é a captura do efeito fixo do tempo para cada ano $t ; \epsilon_{i t}$ é o termo de erro aleatório; e $\beta_{0}, \beta_{1 j}, \beta_{2} \beta 0, \beta 1 \mathrm{j}, \gamma$ e $\delta_{t}$ são os parâmetros do modelo. Os parâmetros $\beta_{1 j}$ e $\beta_{2}$ medem os efeitos do Agroamigo sobre a variável de desfecho, respectivamente, capturando a heterogeneidade pelo tempo de exposição e o volume de cobertura do programa. 
Para aumentar a precisão das estimativas, utilizou-se de variáveis de controle, fatores observáveis variantes no tempo, que podem estar correlacionadas com a implementação do programa e/ou com aumento da produção agropecuária, quais sejam: população rural, porte do município, massa salarial, vínculos ativos, número de faculdades como uma proxy para a educação e os índices de diversificação das produções pecuária e agrícola e indicador de precipitação pluviométrica. Além disso, a utilização do modelo DD com controle para efeito fixo garante tanto o controle das características observáveis dos municípios, que podem influenciar na participação do programa, quanto as características não observáveis, que são fixas no tempo, minimizando possível viés de seleção.

\section{Análise dos Resultados}

Para verificar a hipótese assumida neste estudo de que um maior tempo de exposição ao programa e um maior volume de recursos recebidos produzem um efeito positivo sobre o valor da produção agropecuária, apresentam-se e discutem-se a seguir os modelos utilizados na presente pesquisa, levando-se em consideração o valor da produção agropecuária e sua decomposição (agricultura e pecuária). As análises realizadas nesta seção se restringem aos parâmetros que medem os efeitos potencialmente atribuídos ao programa, sendo as variáveis de controle utilizadas para aumentar a eficiência das estimativas de impacto.

A Tabela 2 apresenta os resultados referentes ao valor da produção total (agropecuária). No modelo inicial, realizou-se uma regressão múltipla com dados agrupados por ano, tendo como variáveis explicativas apenas as dummies de tempo de exposição. Nessa abordagem, menos criteriosa em termos de especificação de variáveis e de controles, observa-se que, a priori, os resultados se mostraram estatisticamente significativos ao nível de até $5 \%$, indicando que, quanto maior o tempo de exposição ao programa, maior o valor da produção agropecuária. Por exemplo, os municípios expostos a dois anos ao Agroamigo conseguem aumentar a produção agropecuária em, aproximadamente, $R \$ 3,6$ milhões quando comparados aos municípios não expostos.

No segundo modelo (coluna 2 da Tabela 2), em que constam as variáveis de tendência, os efeitos se mantêm entre o $8^{\circ}$ e $10^{\circ}$ ano de exposição ao programa, para os quais se observam resultados positivos e significantes. Porém, a partir do terceiro modelo, que considera o volume de recursos repassados pelo Agroamigo (valor), verifica-se que os valores são estatisticamente significativos apenas com 11 anos de exposição ao programa, mas com o efeito negativo.

No quarto modelo, incorporando as variáveis de controle, os resultados também são opostos ao esperado, ou seja, um maior tempo exposto ao Agroamigo afeta negativamente a produção agropecuária. Por exemplo, com 11 anos de exposição, o valor da produção diminui mais de $R \$ 10$ milhões. Os modelos (5) e (6) tratam dos resultados obtidos a partir do emprego dos dados em painel com efeito fixo. Os resultados apontam que não há efeito do programa para o nível de significância considerado.

Analisando-se a variável valor de repasse do programa, que se mostrou com sinal positivo e estatisticamente significativa, constata-se que ela se mantém estável independentemente do modelo. De forma geral, estima-se que, para cada $R \$ 1$ mil emprestado via Agroamigo, há um retorno de menos de $\mathrm{R} \$ 2$ mil no valor da produção total. Apesar da não significância dos coeficientes associados ao tempo de exposição, há um primeiro indício de que o programa gera um retorno positivo para as atividades agropecuárias do Nordeste. 
Tabela 2 - Estimativas do efeito do Programa Agroamigo sobre o valor da produção total (em mil reais), municípios do Nordeste, de 2003 a 2015.

\begin{tabular}{|c|c|c|c|c|c|c|}
\hline & (1) & (2) & (3) & (4) & (5) & (6) \\
\hline \multicolumn{7}{|c|}{$\begin{array}{c}\text { Tempo de exposição ao } \\
\text { Programa Agroamigo }\end{array}$} \\
\hline 1 ano & $\begin{array}{c}1795,840 \\
(1525,381)\end{array}$ & $\begin{array}{c}825,760 \\
(1682,444)\end{array}$ & $\begin{array}{c}-668,770 \\
(1680,892)\end{array}$ & $\begin{array}{l}-1258,867 \\
(1645,146)\end{array}$ & $\begin{array}{l}-333,818 \\
(849,217)\end{array}$ & $\begin{array}{c}258,671 \\
(532,062)\end{array}$ \\
\hline 2 anos & $\begin{array}{l}3574,644^{*} \\
(1525,733)\end{array}$ & $\begin{array}{c}1493,743 \\
(1780,067)\end{array}$ & $\begin{array}{l}-1270,774 \\
(1787,455)\end{array}$ & $\begin{array}{l}-1523,555 \\
(1750,989)\end{array}$ & $\begin{array}{l}-435,573 \\
(964,155)\end{array}$ & $\begin{array}{c}-69,899 \\
(614,385)\end{array}$ \\
\hline 3 anos & $\begin{array}{l}5175,660 * \\
(1527,498)\end{array}$ & $\begin{array}{c}1879,021 \\
(1885,254)\end{array}$ & $\begin{array}{l}-1443,165 \\
(1897,150)\end{array}$ & $\begin{array}{l}-1994,866 \\
(1859,998)\end{array}$ & $\begin{array}{c}-878,817 \\
(1088,234)\end{array}$ & $\begin{array}{c}112,756 \\
(702,147)\end{array}$ \\
\hline 4 anos & $\begin{array}{l}5942,175^{*} \\
(1530,696)\end{array}$ & $\begin{array}{c}2445,138 \\
(2013,793)\end{array}$ & $\begin{array}{l}-1642,033 \\
(2032,842)\end{array}$ & $\begin{array}{l}-2402,709 \\
(1995,284)\end{array}$ & $\begin{array}{l}-1318,212 \\
(1239,923)\end{array}$ & $\begin{array}{c}311,486 \\
(808,721)\end{array}$ \\
\hline 5 anos & $\begin{array}{l}6930,380 * \\
(1538,260)\end{array}$ & $\begin{array}{c}3311,750 \\
(2153,340)\end{array}$ & $\begin{array}{l}-1824,628 \\
(2184,174)\end{array}$ & $\begin{array}{l}-2798,159 \\
(2145,179)\end{array}$ & $\begin{array}{l}-1537,564 \\
(1411,617)\end{array}$ & $\begin{array}{c}567,539 \\
(927,445)\end{array}$ \\
\hline 6 anos & $\begin{array}{l}8617,790 * \\
(1551,193)\end{array}$ & $\begin{array}{c}4149,891 \\
(2282,073)\end{array}$ & $\begin{array}{l}-2434,795 \\
(2333,243)\end{array}$ & $\begin{array}{l}-3314,648 \\
(2292,601)\end{array}$ & $\begin{array}{l}-1942,760 \\
(1585,589)\end{array}$ & $\begin{array}{c}599,841 \\
(1046,933)\end{array}$ \\
\hline 7 anos & $\begin{array}{l}9323,123 * \\
(1643,723)\end{array}$ & $\begin{array}{c}4746,367 \\
(2442,853)\end{array}$ & $\begin{array}{l}-3250,325 \\
(2515,446)\end{array}$ & $\begin{array}{l}-3839,340 \\
(2472,470)\end{array}$ & $\begin{array}{l}-2419,628 \\
(1772,943)\end{array}$ & $\begin{array}{c}250,895 \\
(1171,025)\end{array}$ \\
\hline 8 anos & $\begin{array}{l}12107,070 * \\
(1829,031)\end{array}$ & $\begin{array}{l}7833,467 * \\
(2658,828)\end{array}$ & $\begin{array}{l}-2081,225 \\
(2763,502)\end{array}$ & $\begin{array}{l}-2655,307 \\
(2714,276)\end{array}$ & $\begin{array}{l}-1781,005 \\
(1989,765)\end{array}$ & $\begin{array}{c}2174,019 \\
(1310,785)\end{array}$ \\
\hline 9 anos & $\begin{array}{c}16386,650 * \\
(2044,823)\end{array}$ & $\begin{array}{l}11647,790 * \\
(2921,283)\end{array}$ & $\begin{array}{c}-391,969 \\
(3063,280)\end{array}$ & $\begin{array}{c}-776,129 \\
(3007,475)\end{array}$ & $\begin{array}{c}-503,408 \\
(2227,887)\end{array}$ & $\begin{array}{c}2475,958 \\
(1462,746)\end{array}$ \\
\hline 10 anos & $\begin{array}{c}18278,830 * \\
(2314,187)\end{array}$ & $\begin{array}{l}13102,350 * \\
(3268,818)\end{array}$ & $\begin{array}{l}-1170,333 \\
(3447,936)\end{array}$ & $\begin{array}{l}-1230,079 \\
(3383,645)\end{array}$ & $\begin{array}{l}-1125,311 \\
(2497,209)\end{array}$ & $\begin{array}{c}1604,814 \\
(1632,150)\end{array}$ \\
\hline 11 anos & $\begin{array}{l}9330,153 * \\
(4318,531)\end{array}$ & $\begin{array}{c}4078,990 \\
(5008,882)\end{array}$ & $\begin{array}{c}-11919,030 * \\
(5149,883)\end{array}$ & $\begin{array}{c}-10515,080 * \\
(5044,127)\end{array}$ & $\begin{array}{l}-6267,371 \\
(3248,711)\end{array}$ & $\begin{array}{c}1367,833 \\
(1991,481)\end{array}$ \\
\hline $\begin{array}{c}\text { Valor de repasse } \\
\text { do Programa } \\
\text { Agroamigo }\end{array}$ & & & $\begin{array}{l}12,190 * \\
(0,965)\end{array}$ & $\begin{array}{l}2,462 * \\
(1,010)\end{array}$ & $\begin{array}{l}1,743^{*} \\
(0,615)\end{array}$ & $\begin{array}{l}1,516 * \\
(0,368)\end{array}$ \\
\hline Outros controles & & & & & & \\
\hline Pop. rural & & & & $\begin{array}{l}1,463^{*} \\
(0,054)\end{array}$ & $\begin{array}{l}3,973 * \\
(0,238)\end{array}$ & $\begin{array}{l}2,669 * \\
(0,174)\end{array}$ \\
\hline Trabalhadores & & & & $\begin{array}{l}0,126 * \\
(0,046)\end{array}$ & $\begin{array}{c}0,045 \\
(0,052)\end{array}$ & $\begin{array}{l}1,220 * \\
(0,109)\end{array}$ \\
\hline Massa salarial & & & & $\begin{array}{c}24,625 * \\
(1,748)\end{array}$ & $\begin{array}{l}6,661 * \\
(1,518)\end{array}$ & $\begin{array}{l}-0,581 \\
(1,106)\end{array}$ \\
\hline Faculdades & & & & $\begin{array}{c}-1722,953^{*} \\
(529,629)\end{array}$ & $\begin{array}{c}35,446 \\
(455,116)\end{array}$ & $\begin{array}{l}-212,468 \\
(446,349)\end{array}$ \\
\hline IB-A & & & & $\begin{array}{l}4833,075^{\star} \\
(2103,684)\end{array}$ & $\begin{array}{c}3103,413 \\
(1909,471)\end{array}$ & $\begin{array}{l}2221,834 * \\
(1107,651)\end{array}$ \\
\hline IB-P & & & & $\begin{array}{c}-16743,190 * \\
(2306,744)\end{array}$ & $\begin{array}{c}-10353,470 * \\
(2579,405)\end{array}$ & $\begin{array}{l}-8138,573 * \\
(1572,688)\end{array}$ \\
\hline Desv. prec. & & & & & & $\begin{array}{l}11,969 \\
(6,571)\end{array}$ \\
\hline Constante & $\begin{array}{c}10143,640 * \\
(642,700)\end{array}$ & $\begin{array}{l}8701,003 * \\
(1381,835)\end{array}$ & $\begin{array}{l}8701,003 * \\
(1377,139)\end{array}$ & $\begin{array}{l}-8717,494 * \\
(1882,493)\end{array}$ & & \\
\hline
\end{tabular}


Tabela 2 - Continuação...

\begin{tabular}{|c|c|c|c|c|c|c|}
\hline & (1) & (2) & (3) & (4) & (5) & (6) \\
\hline \multicolumn{7}{|c|}{$\begin{array}{c}\text { Tempo de exposição ao } \\
\text { Programa Agroamigo }\end{array}$} \\
\hline Tendência & & $x$ & $x$ & $x$ & $x$ & $x$ \\
\hline Controles & & & & $x$ & $x$ & $x$ \\
\hline Efeito fixo & & & & & $x$ & $x$ \\
\hline Observações & 23254 & 23254 & 23254 & 23254 & 23254 & 13455 \\
\hline
\end{tabular}

Fonte: elaborada pelos autores. Erro-padrão robusto entre parênteses. ${ }^{*} \mathrm{p}<0,05$.

Para controlar o papel da variação climática sobre a produção agropecuária, incorporouse uma medida que capta o índice de variação pluviométrica (Desv. prec.) no modelo (6) da Tabela 2. Essa variável, como esperado, relaciona-se positivamente com a produção agropecuária municipal, porém a inclusão desse novo controle no modelo de regressão não gerou alterações substantivas nos parâmetros associados com o programa. Dessa forma, analisando os modelos iniciais, conclui-se, a priori, que o Agroamigo tem efeito positivo sobre a produção. Portanto, quando não existe o controle dos modelos pelas variáveis explicativas e pelo efeito fixo dos municípios, há uma sobreidentificação de efeito do Agroamigo na produção agropecuária municipal.

Resultados semelhantes são encontrados nas estimativas referentes às análises específicas apenas sobre o valor da produção agrícola. Ao analisar a Tabela 3, observam-se, em geral, resultados similares aos encontrados para o caso da avaliação sobre a produção total. Não obstante, diferenças no coeficiente do valor de empréstimos concedidos pelo Agroamigo não se mostram estaticamente significativas para o caso agricultura. Dessa maneira, de acordo com os resultados oriundos do modelo com melhor especificação, modelo (6) da Tabela 3, não se identificaram efeitos do Programa Agroamigo sobre a produção agrícola dos municípios nordestinos.

Como a maior parte dos recursos do programa é destinada à pecuária - pela lógica da redução dos riscos do pagamento dos empréstimos -, o Agroamigo, por meio dos agentes de crédito, pode ter induzido os agricultores a investirem mais nesse setor em detrimento da atividade agrícola. Com isso, um dos possíveis resultados é que o programa pode ter incentivado uma alteração no sistema de produção no Nordeste.

De fato, o presente estudo só conseguiu identificar efeitos do Agroamigo mais expressivos no valor da produção pecuária, conforme pode ser observado na Tabela 4. Os resultados indicam, com base no modelo (6), efeitos positivos e significativos estatisticamente a 5\%, tanto no volume de microcréditos concedidos quanto para as localidades com pelo menos sete anos de exposição aos benefícios do programa. Os municípios, por exemplo, com 11 anos de exposição ao programa possuem, em média, $\mathrm{R} \$ 1,3$ milhão a mais no valor da produção pecuária. Além disso, para cada $\mathrm{R} \$ 1$ mil emprestados pelo BNB à agricultura familiar, nota-se um aumento de pouco mais de $\mathrm{R} \$ 1$ mil no valor da produção. Esses resultados apresentam pouca sensibilidade ao controle das condições pluviométricas realizado no modelo (6), o que corrobora a robustez das estimativas de impacto do Agroamigo. 
Tabela 3 - Estimativas do efeito do Programa Agroamigo sobre o valor da produção agrícola (em mil reais), municípios do Nordeste, de 2003 a 2015.

\begin{tabular}{|c|c|c|c|c|c|c|}
\hline & (1) & (2) & (3) & (4) & (5) & (6) \\
\hline \multicolumn{7}{|c|}{$\begin{array}{c}\text { Tempo de exposição ao } \\
\text { Programa Agroamigo }\end{array}$} \\
\hline 1 ano & $\begin{array}{c}1333,571 \\
(1509,654)\end{array}$ & $\begin{array}{c}438,495 \\
(1665,055)\end{array}$ & $\begin{array}{c}-793,648 \\
(1665,268)\end{array}$ & $\begin{array}{l}-1331,817 \\
(1636,972)\end{array}$ & $\begin{array}{l}-252,809 \\
(841,657)\end{array}$ & $\begin{array}{l}404,169 \\
(514,199)\end{array}$ \\
\hline 2 anos & $\begin{array}{c}2853,240 \\
(1510,003)\end{array}$ & $\begin{array}{c}813,024 \\
(1761,669)\end{array}$ & $\begin{array}{l}-1466,142 \\
(1770,840)\end{array}$ & $\begin{array}{l}-1713,823 \\
(1742,290)\end{array}$ & $\begin{array}{l}-387,391 \\
(955,573)\end{array}$ & $\begin{array}{c}125,585 \\
(593,758)\end{array}$ \\
\hline 3 anos & $\begin{array}{l}4257,950^{*} \\
(1511,750)\end{array}$ & $\begin{array}{c}933,501 \\
(1865,769)\end{array}$ & $\begin{array}{l}-1805,426 \\
(1879,516)\end{array}$ & $\begin{array}{l}-2311,017 \\
(1850,757)\end{array}$ & $\begin{array}{c}-892,937 \\
(1078,547)\end{array}$ & $\begin{array}{l}243,196 \\
(678,574)\end{array}$ \\
\hline 4 anos & $\begin{array}{l}4779,720 * \\
(1514,915)\end{array}$ & $\begin{array}{c}1141,624 \\
(1992,979)\end{array}$ & $\begin{array}{l}-2227,985 \\
(2013,947)\end{array}$ & $\begin{array}{l}-2926,997 \\
(1985,371)\end{array}$ & $\begin{array}{l}-1436,912 \\
(1228,886)\end{array}$ & $\begin{array}{l}461,503 \\
(781,570)\end{array}$ \\
\hline 5 anos & $\begin{array}{l}5531,636 * \\
(1522,401)\end{array}$ & $\begin{array}{c}1592,300 \\
(2131,084)\end{array}$ & $\begin{array}{l}-2642,311 \\
(2163,871)\end{array}$ & $\begin{array}{l}-3562,317 \\
(2134,521)\end{array}$ & $\begin{array}{l}-1786,145 \\
(1399,051)\end{array}$ & $\begin{array}{c}664,785 \\
(896,308)\end{array}$ \\
\hline 6 anos & $\begin{array}{l}6952,834^{*} \\
(1535,200)\end{array}$ & $\begin{array}{c}1989,685 \\
(2258,486)\end{array}$ & $\begin{array}{l}-3438,963 \\
(2311,555)\end{array}$ & $\begin{array}{l}-4287,663 \\
(2281,210)\end{array}$ & $\begin{array}{l}-2298,275 \\
(1571,475)\end{array}$ & $\begin{array}{c}721,197 \\
(1011,784)\end{array}$ \\
\hline 7 anos & $\begin{array}{l}7281,716 * \\
(1626,776)\end{array}$ & $\begin{array}{c}2096,667 \\
(2417,604)\end{array}$ & $\begin{array}{l}-4496,089 \\
(2492,064)\end{array}$ & $\begin{array}{l}-5104,002 * \\
(2460,186)\end{array}$ & $\begin{array}{l}-2956,418 \\
(1757,161)\end{array}$ & $\begin{array}{c}394,654 \\
(1131,710)\end{array}$ \\
\hline 8 anos & $\begin{array}{l}9354,242 * \\
(1810,174)\end{array}$ & $\begin{array}{c}4385,876 \\
(2631,346)\end{array}$ & $\begin{array}{l}-3788,147 \\
(2737,815)\end{array}$ & $\begin{array}{l}-4386,837 \\
(2700,791)\end{array}$ & $\begin{array}{l}-2631,613 \\
(1972,053)\end{array}$ & $\begin{array}{c}2211,950 \\
(1266,777)\end{array}$ \\
\hline 9 anos & $\begin{array}{l}13183,270 * \\
(2023,741)\end{array}$ & $\begin{array}{l}7608,489 * \\
(2891,089)\end{array}$ & $\begin{array}{l}-2317,516 \\
(3034,806)\end{array}$ & $\begin{array}{l}-2743,819 \\
(2992,533)\end{array}$ & $\begin{array}{l}-1564,340 \\
(2208,055)\end{array}$ & $\begin{array}{c}2533,965 \\
(1413,637)\end{array}$ \\
\hline 10 anos & $\begin{array}{l}14142,700 * \\
(2290,328)\end{array}$ & $\begin{array}{l}8011,977 * \\
(3235,032)\end{array}$ & $\begin{array}{l}-3754,924 \\
(3415,887)\end{array}$ & $\begin{array}{l}-3881,917 \\
(3366,834)\end{array}$ & $\begin{array}{l}-2670,258 \\
(2474,979)\end{array}$ & $\begin{array}{c}1548,942 \\
(1577,353)\end{array}$ \\
\hline 11 anos & $\begin{array}{c}5044,059 \\
(4274,009)\end{array}$ & $\begin{array}{l}-1194,549 \\
(4957,111)\end{array}$ & $\begin{array}{c}-14383,880 * \\
(5102,014)\end{array}$ & $\begin{array}{c}-13157,820 * \\
(5019,066)\end{array}$ & $\begin{array}{c}-7966,797 * \\
(3219,792)\end{array}$ & $\begin{array}{c}1218,695 \\
(1924,621)\end{array}$ \\
\hline $\begin{array}{c}\text { Valor de repasse } \\
\text { do Programa } \\
\text { Agroamigo }\end{array}$ & & & $\begin{array}{l}10,050 * \\
(0,956)\end{array}$ & $\begin{array}{l}1,429 \\
(1,005)\end{array}$ & $\begin{array}{l}0,792 \\
(0,610)\end{array}$ & $\begin{array}{c}0,491 \\
(0,356)\end{array}$ \\
\hline $\begin{array}{l}\text { Outros } \\
\text { controles }\end{array}$ & & & & & & \\
\hline Pop. rural & & & & $\begin{array}{l}1,296 * \\
(0,054)\end{array}$ & $\begin{array}{l}3,692 * \\
(0,236)\end{array}$ & $\begin{array}{l}2,136 * \\
(0,168)\end{array}$ \\
\hline Trabalhadores & & & & $\begin{array}{l}0,124 * \\
(0,046)\end{array}$ & $\begin{array}{c}0,061 \\
(0,052)\end{array}$ & $\begin{array}{l}1,165^{*} \\
(0,106)\end{array}$ \\
\hline Massa salarial & & & & $\begin{array}{c}23,407 * \\
(1,739)\end{array}$ & $\begin{array}{l}6,545^{*} \\
(1,504)\end{array}$ & $\begin{array}{l}-0,576 \\
(1,069)\end{array}$ \\
\hline Faculdades & & & & $\begin{array}{c}-1742,326^{\star} \\
(526,997)\end{array}$ & $\begin{array}{c}-96,601 \\
(451,065)\end{array}$ & $\begin{array}{l}-697,039 \\
(431,364)\end{array}$ \\
\hline IB-A & & & & $\begin{array}{l}5058,096 * \\
(2093,233)\end{array}$ & $\begin{array}{c}2898,066 \\
(1892,473)\end{array}$ & $\begin{array}{c}1884,255 \\
(1070,464)\end{array}$ \\
\hline IB-P & & & & $\begin{array}{c}-10158,030 * \\
(2295,283)\end{array}$ & $\begin{array}{l}-6365,130 * \\
(2556,443)\end{array}$ & $\begin{array}{l}-3805,284^{*} \\
(1519,888)\end{array}$ \\
\hline Desv. prec. & & & & & & $\begin{array}{l}16,519 * \\
(8,284)\end{array}$ \\
\hline Constante & $\begin{array}{c}8838,743 * \\
(636,074)\end{array}$ & $\begin{array}{l}7589,938 * \\
(1367,553)\end{array}$ & $\begin{array}{l}7589,938 * \\
(1364,339)\end{array}$ & $\begin{array}{c}-10132,880 * \\
(1873,140)\end{array}$ & & \\
\hline
\end{tabular}


Tabela 3 - Continuação...

\begin{tabular}{|c|c|c|c|c|c|c|}
\hline & (1) & (2) & (3) & (4) & (5) & (6) \\
\hline \multicolumn{7}{|c|}{$\begin{array}{c}\text { Tempo de exposição ao } \\
\text { Programa Agroamigo }\end{array}$} \\
\hline Tendência & & $x$ & $x$ & $x$ & $x$ & $x$ \\
\hline Controles & & & & $x$ & $x$ & $x$ \\
\hline Efeito fixo & & & & & $x$ & $x$ \\
\hline Observações & 23254 & 23254 & 23254 & 23254 & 23254 & 13455 \\
\hline
\end{tabular}

Fonte: elaborada pelos autores. Erro-padrão robusto entre parênteses. ${ }^{*} p<0,05$.

Tabela 4 - Estimativas do efeito do Programa Agroamigo sobre o valor da produção pecuária (em mil reais), municípios do Nordeste, de 2003 a 2015.

\begin{tabular}{|c|c|c|c|c|c|c|}
\hline & (1) & (2) & (3) & (4) & (5) & (6) \\
\hline \multicolumn{7}{|c|}{$\begin{array}{c}\text { Tempo de exposição ao } \\
\text { Programa Agroamigo }\end{array}$} \\
\hline 1 ano & $\begin{array}{l}462,216^{*} \\
(151,350)\end{array}$ & $\begin{array}{l}387,105^{\star} \\
(166,860)\end{array}$ & $\begin{array}{c}124,734 \\
(165,479)\end{array}$ & $\begin{array}{c}73,067 \\
(159,040)\end{array}$ & $\begin{array}{l}-81,228 \\
(97,248)\end{array}$ & $\begin{array}{l}-145,497 \\
(141,844)\end{array}$ \\
\hline 2 anos & $\begin{array}{l}721,353 * \\
(151,385)\end{array}$ & $\begin{array}{l}680,461 * \\
(176,542)\end{array}$ & $\begin{array}{c}195,139 \\
(175,970)\end{array}$ & $\begin{array}{c}190,470 \\
(169,273)\end{array}$ & $\begin{array}{c}-48,365 \\
(110,410)\end{array}$ & $\begin{array}{l}-195,484 \\
(163,791)\end{array}$ \\
\hline 3 anos & $\begin{array}{l}917,939 * \\
(151,560)\end{array}$ & $\begin{array}{l}945,480 * \\
(186,974)\end{array}$ & $\begin{array}{c}362,256 \\
(186,769)\end{array}$ & $\begin{array}{c}316,671 \\
(179,811)\end{array}$ & $\begin{array}{c}14,051 \\
(124,619)\end{array}$ & $\begin{array}{c}13,439 \\
(187,188)\end{array}$ \\
\hline 4 anos & $\begin{array}{l}1162,489 * \\
(151,877)\end{array}$ & $\begin{array}{l}1303,211 * \\
(199,722)\end{array}$ & $\begin{array}{l}585,691 * \\
(200,128)\end{array}$ & $\begin{array}{l}524,680 * \\
(192,889)\end{array}$ & $\begin{array}{c}118,401 \\
(141,989)\end{array}$ & $\begin{array}{c}150,017 \\
(215,600)\end{array}$ \\
\hline 5 anos & $\begin{array}{l}1398,762 * \\
(152,628)\end{array}$ & $\begin{array}{l}1719,015^{*} \\
(213,562)\end{array}$ & $\begin{array}{l}817,303^{*} \\
(215,026)\end{array}$ & $\begin{array}{l}764,549 * \\
(207,380)\end{array}$ & $\begin{array}{c}248,221 \\
(161,651)\end{array}$ & $\begin{array}{c}197,246 \\
(247,251)\end{array}$ \\
\hline 6 anos & $\begin{array}{l}1664,951 * \\
(153,911)\end{array}$ & $\begin{array}{l}2159,668 * \\
(226,330)\end{array}$ & $\begin{array}{l}1003,700 * \\
(229,701)\end{array}$ & $\begin{array}{l}973,407 * \\
(221,631)\end{array}$ & $\begin{array}{c}355,093 \\
(181,573)\end{array}$ & $\begin{array}{c}321,355 \\
(179,106)\end{array}$ \\
\hline 7 anos & $\begin{array}{r}2041,486 * \\
(163,092)\end{array}$ & $\begin{array}{c}2649,254 * \\
(242,275)\end{array}$ & $\begin{array}{c}1245,402 * \\
(247,639)\end{array}$ & $\begin{array}{c}1265,240 * \\
(239,020)\end{array}$ & $\begin{array}{l}536,469 * \\
(203,028)\end{array}$ & $\begin{array}{l}443,759 * \\
(212,188)\end{array}$ \\
\hline 8 anos & $\begin{array}{c}2752,759 * \\
(181,479)\end{array}$ & $\begin{array}{c}3446,986 * \\
(263,695)\end{array}$ & $\begin{array}{c}1706,421 * \\
(272,059)\end{array}$ & $\begin{array}{c}1732,048 * \\
(262,396)\end{array}$ & $\begin{array}{l}850,270 * \\
(227,857)\end{array}$ & $\begin{array}{l}677,931 * \\
(249,447)\end{array}$ \\
\hline 9 anos & $\begin{array}{c}3203,307 * \\
(202,890)\end{array}$ & $\begin{array}{c}4038,665^{*} \\
(289,725)\end{array}$ & $\begin{array}{c}1925,036 * \\
(301,572)\end{array}$ & $\begin{array}{c}1968,234 * \\
(290,740)\end{array}$ & $\begin{array}{c}1060,576 * \\
(255,125)\end{array}$ & $\begin{array}{c}1008,007 * \\
(389,959)\end{array}$ \\
\hline 10 anos & $\begin{array}{c}4136,064 * \\
(229,616)\end{array}$ & $\begin{array}{c}5089,661 * \\
(324,192)\end{array}$ & $\begin{array}{c}2584,035 * \\
(339,440)\end{array}$ & $\begin{array}{c}2652,384 * \\
(327,105)\end{array}$ & $\begin{array}{c}1544,527 * \\
(285,967)\end{array}$ & $\begin{array}{r}1355,872 * \\
(335,121)\end{array}$ \\
\hline 11 anos & $\begin{array}{c}4286,021 * \\
(428,490)\end{array}$ & $\begin{array}{c}5272,800 * \\
(496,767)\end{array}$ & $\begin{array}{c}2464,282^{*} \\
(506,992)\end{array}$ & $\begin{array}{c}2643,445^{*} \\
(487,628)\end{array}$ & $\begin{array}{c}1698,922^{*} \\
(372,025)\end{array}$ & $\begin{array}{c}1349,139 * \\
(390,916)\end{array}$ \\
\hline $\begin{array}{l}\text { Valor de } \\
\text { repasse } \\
\text { do Programa } \\
\text { Agroamigo }\end{array}$ & & & $\begin{array}{l}2,140 * \\
(0,095)\end{array}$ & $1,033^{*}$ & $0,952 *$ & $1,025^{*}$ \\
\hline Outros controles & & & & & & \\
\hline Pop. rural & & & & $\begin{array}{l}0,167 * \\
(0,005)\end{array}$ & $\begin{array}{l}0,282^{*} \\
(0,027)\end{array}$ & $\begin{array}{l}0,533^{*} \\
(0,046)\end{array}$ \\
\hline Trabalhadores & & & & $\begin{array}{c}0,003 \\
(0,004)\end{array}$ & $\begin{array}{l}-0,016 * \\
(0,006)\end{array}$ & $\begin{array}{c}0,055 \\
(0,029)\end{array}$ \\
\hline Massa salarial & & & & $\begin{array}{l}1,217^{*} \\
(0,169)\end{array}$ & $\begin{array}{c}0,116 \\
(0,174)\end{array}$ & $\begin{array}{l}-0,005 \\
(0,295)\end{array}$ \\
\hline Faculdades & & & & $\begin{array}{c}17,769 \\
(51,201)\end{array}$ & $\begin{array}{c}132,414 * \\
(52,117)\end{array}$ & $\begin{array}{l}484,572 * \\
(118,994)\end{array}$ \\
\hline IB-A & & & & $\begin{array}{l}-225,504 \\
(203,368)\end{array}$ & $\begin{array}{c}205,348 \\
(218,662)\end{array}$ & $\begin{array}{c}337,579 \\
(295,293)\end{array}$ \\
\hline
\end{tabular}


Tabela 4 - Continuação...

\begin{tabular}{|c|c|c|c|c|c|c|}
\hline & (1) & (2) & (3) & (4) & (5) & (6) \\
\hline \multicolumn{7}{|c|}{$\begin{array}{l}\text { Tempo de exposição ao } \\
\text { Programa Agroamigo }\end{array}$} \\
\hline IB-P & & & & $\begin{array}{c}-6585,241 * \\
(222,999)\end{array}$ & $\begin{array}{c}-3989,354 * \\
(295,379)\end{array}$ & $\begin{array}{c}-4333,290 * \\
(419,269)\end{array}$ \\
\hline Desv. prec. & & & & & & $\begin{array}{l}4,550 * \\
(2,285)\end{array}$ \\
\hline Constante & $\begin{array}{c}1304,973 * \\
(63,769)\end{array}$ & $\begin{array}{l}1111,081 * \\
(137,047)\end{array}$ & $\begin{array}{l}1111,081 * \\
(135,576)\end{array}$ & $\begin{array}{l}1415,640 * \\
(181,985)\end{array}$ & & \\
\hline Tendência & & $x$ & $x$ & $x$ & $x$ & $x$ \\
\hline Controles & & & & $x$ & $x$ & $x$ \\
\hline Efeito fixo & & & & & $x$ & $x$ \\
\hline Observações & 23254 & 23254 & 23254 & 23254 & 23254 & 13455 \\
\hline
\end{tabular}

Fonte: elaborada pelos autores. Erro-padrão robusto entre parênteses. ${ }^{*} \mathrm{p}<0,05$.

Com a finalidade de uma melhor identificação dos impactos do Agroamigo, uma vez que na modelagem proposta esses efeitos são mensurados por um total de até 12 parâmetros (tempo de exposição e valor de repasse do programa), a Tabela 5 apresenta, de forma consolidada e por ano, indicadores que permitem avaliar uma razão benefício-custo do programa. Especificamente, reportam-se o valor da produção total (agrícola mais pecuária), o valor da produção pecuária, o valor dos microcréditos concedidos pelo Agroamigo e o valor estimado do efeito global do programa entre os anos de 2005 e 2015 . Ademais, as três últimas colunas dimensionam a magnitude incrementada pelo programa à atividade produtiva no Nordeste, com destaque para o indicador de análise benefício-custo (ABC). Todos os valores monetários estão mensurados a preços constantes do ano de 2015.

Tabela 5 - Análise custo-efetividade do Programa Agroamigo sobre o valor da produção agropecuária, Nordeste brasileiro, de 2005 a 2015

\begin{tabular}{|c|c|c|c|c|c|c|c|}
\hline \multirow{3}{*}{ Ano } & \multicolumn{4}{|c|}{ Em mil reais } & \multicolumn{2}{|c|}{$\begin{array}{l}\text { Participação do } \\
\text { efeito (em \%) }\end{array}$} & \multirow[b]{2}{*}{ ABC } \\
\hline & $\begin{array}{l}\text { Valor da } \\
\text { produção } \\
\text { total }\end{array}$ & $\begin{array}{l}\text { Valor da } \\
\text { produção } \\
\text { pecuária }\end{array}$ & $\begin{array}{c}\text { Valor de } \\
\text { repasse do } \\
\text { Programa } \\
\text { Agroamigo }\end{array}$ & $\begin{array}{l}\text { Efeito do } \\
\text { Programa } \\
\text { Agroamigo }\end{array}$ & $\begin{array}{l}\text { Produção } \\
\text { total }\end{array}$ & $\begin{array}{l}\text { Produção } \\
\text { pecuária }\end{array}$ & \\
\hline & A & B & C & D & D/A & D/B & $\mathrm{D} / \mathrm{C}$ \\
\hline 2005 & 16.759.965 & 2.525 .807 & 16.804 & 15.991 & 0,1 & 0,6 & 0,95 \\
\hline 2006 & 18.314 .211 & 2.849 .084 & 140.901 & 134.086 & 0,7 & 4,7 & 0,95 \\
\hline 2007 & 20.631 .111 & 3.197 .067 & 238.366 & 226.837 & 1,1 & 7,1 & 0,95 \\
\hline 2008 & 25.968 .030 & 3.611 .674 & 226.000 & 215.069 & 0,8 & 6,0 & 0,95 \\
\hline 2009 & 25.552 .467 & 4.077 .810 & 397.891 & 378.646 & 1,5 & 9,3 & 0,95 \\
\hline 2010 & 26.683 .054 & 4.333 .023 & 535.586 & 509.680 & 1,9 & 11,8 & 0,95 \\
\hline 2011 & 32.704 .289 & 4.741 .507 & 695.639 & 762.312 & 2,3 & 16,1 & 1,10 \\
\hline 2012 & 32.500 .892 & 5.178 .999 & 823.105 & 1.213 .210 & 3,7 & 23,4 & 1,47 \\
\hline 2013 & 34.304 .134 & 5.796 .811 & 1.126 .614 & 1.813 .252 & 5,3 & 31,3 & 1,61 \\
\hline 2014 & 40.493 .658 & 6.345 .197 & 1.379 .258 & 2.456 .805 & 6,1 & 38,7 & 1,78 \\
\hline 2015 & 42.085 .903 & 7.305 .538 & 1.649 .818 & 3.285 .836 & 7,8 & 45,0 & 1,99 \\
\hline TOTAL & 315.997 .714 & 49.962 .517 & 7.229.981 & 11.011 .722 & 3,5 & 22,0 & 1,52 \\
\hline
\end{tabular}

Fonte: elaborada pelos autores. Nota: valores corrigidos monetariamente pelo Índice Nacional de Preços ao Consumidor Amplo (IPCA), tendo 2015 como período de referência. 
Os cálculos da coluna D referentes ao efeito global do Agroamigo foram realizados com base nos parâmetros oriundos do modelo com a especificação mais completa considerada nesta pesquisa. Neste caso, apenas se levaram em conta as estimativas de impacto no valor da produção pecuária do modelo (6) da Tabela 4, pois foram os resultados com o maior quantitativo de efeitos associados ao programa, com significância estatística de até $5 \%$.

A partir dos indicadores calculados, observa-se que o Programa Agroamigo acumulou, em uma década, apenas mensurando o seu papel nas atividades agropecuárias, uma relação benefício-custo favorável, haja vista que, para cada $\mathrm{R} \$ 1,00$ aplicado no programa, houve um retorno de $\mathrm{R} \$ 1,52$ na produção agropecuária da região Nordeste. Em termos relativos, os valores incrementados associados ao programa responderam por 3,5\% do valor da produção agropecuária total e de $22 \%$ do valor da produção pecuária, sendo esses valores crescentes com o passar do tempo, atingindo em 2015 , respectivamente, $7,8 \%$ e $45 \%$.

Deve-se dimensionar bem os achados encontrados, uma vez que eles são consistentes com a estratégia desenvolvida pelo BNB. De acordo com Aquino \& Teixeira (2005), o programa se encontra altamente concentrado em atividades pecuárias, com cerca de $75 \%$ dos empréstimos voltados para essa atividade; logo, esperava-se que os efeitos ficassem limitados ao citado setor. Para o ano de 2015, os achados expostos na Tabela 5 mostram o importante papel do Agroamigo, sobretudo em períodos prolongados de seca (como vivenciado no semiárido do Nordeste no período investigado), na pecuária nordestina, dado que o efeito global do programa responde por $45 \%$ da produção. Ainda, os resultados encontrados nesta pesquisa estão condizentes com os estudos internacionais de Shah et al. (2015), Sulemana \& Adjei (2015) e Akwaa-Sekyi (2013 e, no Brasil, com os trabalhos de Neri (2012) e Abramovay et al. (2013), que veem o microcrédito como um mecanismo de melhoria na qualidade de vida dos pequenos produtores.

\section{Considerações Finais}

A partir das análises dos modelos de avaliação de impacto, identifica-se que o microcrédito rural produziu um efeito positivo no valor da produção pecuária. O estudo também apresenta evidências de que, pelo menos nessa atividade, há um retorno econômico do valor investido pelo programa de cerca de 50\% durante o período de 2005 a 2015, indicando que o Agroamigo pode servir como um mecanismo de proteção para assegurar a produção e de estímulo para o crescimento da atividade. Para o setor agrícola, não há indícios de que o Agroamigo esteja sendo efetivo. Isso pode estar associado, em especial, ao direcionamento dos empréstimos para a pecuária, que responde por 3/4 do total do Agroamigo, de maneira que o valor relativamente pequeno do benefício concedido ao pequeno agricultor não seja suficiente para incrementar a produção agrícola, uma vez que os custos produtivos são altos, principalmente em períodos de seca.

A presente pesquisa espera contribuir com a literatura por apresentar resultados sobre o efeito do microcrédito rural para atividade produtiva. Uma análise para os municípios ajuda a perceber o efeito em uma perspectiva global, embora o fato da não disponibilidade de dados desagregados entre a agricultura patronal e familiar impeça uma mensuração mais apurada dos efeitos dos empréstimos sobre a parcela da produção realizada pelos pequenos produtores. Por isso, novos estudos podem lançar luz a essas questões.

Ademais, os impactos mensurados neste presente estudo ficaram restritos apenas a medidas da produção agropecuária, porém é possível que o programa impacte também em questões sociais como aumento da renda familiar, concentração de renda, migração e segurança alimentar e nutricional. Contudo, a indisponibilidade de informações dessas dimensões em nível municipal para o período analisado não permitiu a avaliação do Agroamigo nessa perspectiva. Por fim, os achados encontrados evidenciam que o programa é relevante para as atividades produtivas do Nordeste, inclusive pela sua relação custobenefício favorável, que foi medida apenas por uma única dimensão. 


\section{Referências}

Abramovay, R., Madeira, G. A., Rodrigues Júnior, M., Gonçalves, M. F., Maciel, I. S. R., \& Santos, R. A. (2013). Cinco anos de Agroamigo: retrato público e efeitos do programa. Fortaleza: Banco do Nordeste do Brasil.

Agbola, F., Acupan, A., \& Mahmood, A. (2017). Does microfinance reduce poverty? New evidence from Northeastern Mindanao, the Philippines. Journal of Rural Studies, 50, 159-171. http://dx.doi.org/10.1016/j.jrurstud.2016.11.005

Akwaa-Sekyi, E. K. (2013). Impact of micro credit on rural farming activities: the case of farming communities within Sunyani area. Management Science and Engineering, 7(4), 23-29.

Alam, R. (1988). Role of targeted credit programmes in promoting employment and productivity of the poor in Bangladesh. Bangladesh Development Studies, 22(2-3), 49-92.

Aquino, J. R., \& Bastos, F. (2015). Dez anos do programa agroamigo na região nordeste: evolução, resultados e limites para o fortalecimento da agricultura familiar. Revista Economica do Nordeste, 46 139-160.

Aquino, J. R., \& Teixeira, O. A. (2005). Agricultura familiar, crédito e mediação institucional: a experiência do pronaf em são miguel, no nordeste brasileiro. Revista Cuadernos de Desarrollo Rural, 2(54), 1.

Armendariz, B., \& Morduch, J. (2005). The economics of microfinance. American Journal of Agricultural Economics, 1, 361.

Ashaolu, O., Momoh, S., Phillip, B., \& Tijani, I. (2011). Microcredit effect on agricultural productivity: a comparative analysis of rural farmers in Ogun State, Nigeria. International Journal of Applied Agricultural and Apicultural Research, 7(1), 23-35.

Baiardi, A., Alencar, C. M. M., Souza, V. S., \& Oliveira, M. F. G. (2015). Percepção de mutuários do agroamigo no município de Amargosa - BA. Revista Economica do Nordeste, 46, 39-54.

Banco do Nordeste - BNB. (2016). A história do banco se confunde com a história da transformação do Nordeste. Fortaleza. Recuperado em 18 de junho de 2016, de http://www.bnb.gov.br/historico

Banco Mundial. (2008). Relatório sobre o desenvolvimento mundial de 2008: agricultura para o desenvolvimento (34 p.). Washington.

Banerjee, A., \& Duflo, E. (2011). Poor economics: a radical rethinking of the way to fight global poverty. New York: Public Affairs.

Banerjee, A., Duflo, E., Glennerster, R., \& Kinnan, C. (2015a). The miracle of microfinance? evidence from a randomized evaluation. American Economic Journal. Applied Economics, 7(1), 22-53. http://dx.doi.org/10.1257/app.20130533

Banerjee, A., Karlan, D., \& Zinman, J. (2015b). Six randomized evaluations of microcredit: Introduction and further steps. American Economic Journal. Applied Economics, 7(1), 1-21. http://dx.doi.org/10.1257/app.20140287

Bateman, M., \& Chang, H. (2012). Microfinance and the Illusion of development: from hubris to nemesis in thirty years. World Economic Review, 1, 13-36.

Batista, H., \& Neder, H. D. (2014). Efeitos do Pronaf sobre a pobreza rural no Brasil (2001-2009). Revista de Economia e Sociologia Rural, 52(Suppl.1), 147. http://dx.doi.org/10.1590/S010320032014000600008

Baumgartner, S., \& Quaas, M. F. (2010). Managing increasing environmental risks through agrobiodiversity and agroenvironmental policies. Agricultural Economics, 41(5), 483-496. http://dx.doi.org/10.1111/j.1574-0862.2010.00460.x

CEDA Archive. (2019). Recuperado em 28 de março de 2019, de http://data.ceda.ac.uk/

Chen, M., \& Snodgrass, D. (2001). Managing resources, activities, and risks in urban India: an impact assessment of the SEWA bank. Washington.

Coleman, B. (2006). Microfinance in northeast Thailand: who benefits and how much? World Development, 34(9), 1612-1638. http://dx.doi.org/10.1016/j.worlddev.2006.01.006

Conti, B. M., \& Roitman, F. B. (2011). Pronaf uma análise da evolução das fontes de recursos utilizadas no programa. Revista do BNDES, 35, 131-168.

Dong, F., Lu, J., \& Featherstone, A. M. (2010). Effects of credit constraints on productivity and rural household income in China. lowa: Iowa State University.

Feder, G., Lau, L. J., Lin, J., \& Luo, X. (1990). The relationship between credit and productivity in chinese agriculture: a microeconomic model of disequilibrium. American Journal of Agricultural Economics, 72(5), 1151-1157. http://dx.doi.org/10.2307/1242524 
França, C. G., Grossi, M. E., \& Marques, V. P. M. (2009). O censo agropecuário 2006 e a agricultura familiar no Brasil. Brasília: MDA.

Galiani, S., Gertler, P., \& Schargrodsky, E. (2005). Water for Life: The Impact of the Privatization of Water Services on Child Mortality. Journal of Political Economy, 113(1), 83-120. http://dx.doi.org/10.1086/426041

Gazolla, M., \& Schneider, S. (2013). Qual "fortalecimento"da agricultura familiar? Uma análise do Pronaf crédito de custeio e investimento no Rio Grande do Sul. Revista de Economia e Sociologia Rural, 51(1), 45-68. http://dx.doi.org/10.1590/S0103-20032013000100003

Guanziroli, C. (2007). PRONAF dez anos depois: resultados e perspectivas para o desenvolvimento rural. Revista de Economia e Sociologia Rural, 45(2), 301-328. https://doi.org/10.1590/S010320032007000200004

Goldberg, N. (2005). Measuring the Impact of Microfinance: taking stock of what we know (Publication Series). Washington: Grameen Foundation.

Guilhoto, J. J. M., Azzoni, C. R., Silveira, F. G., \& Moreira, G. R. C. (2007). PIB da Agricultura Familiar: BrasilEstados (NEAD Estudos, No. 19). Brasília: MDA.

Guirkinger, C., \& Boucher, S. R. (2007). Credit constraints and productivity in peruvian agriculture. University of California.

Hermes, N., \& Lensink, R. (2007). The empirics of microfinance: what do we know? Economic Journal, 117(517), F1-F10.

Hossain, M. (1988). Credit for alleviation of rural poverty: the Grameen Bank in Bangladesh. Bangladesh Institute of Development Studies.

Hulme, D., \& Mosle, P. (1996). Finance against poverty. London: Routledge.

Karlan, D. (2007). Social connections and group banking. Economic Journal, 117(517), F52-F84.

Khandker, S. (2005). Microfinance and poverty: evidence using panel data from Bangladesh. The World Bank Economic Review, 19(2), 263-286. http://dx.doi.org/10.1093/wber/lhi008

Koloma, Y., \& Aila, H. (2014). Gendered impact of microcredit in Mali: an evaluation by propensity score matching. Strategic Change, 23(7-8), 517-530.

Lin, B. B. (2011). Resilience in agriculture through crop diversification: adaptive management for environmental change. Bioscience, 61(3), 183-193. http://dx.doi.org/10.1525/bio.2011.61.3.4

Lowder, S., Skoet, J., \& Singh, S. (2014). What do we really know about the number and distribution of farms and family farms worldwide? Rome: FAO.

Maia, G. B. S., \& Pinto, A. R. (2015). Agroamigo: uma análise de sua importância no desempenho do pronaf b. Revista Econômica do Nordeste, Fortaleza. Banco do Nordeste do Brasil, 46(Supl.), 1.

Matos, F., Macambira, J., \& Cacciamali, M. C. (2014). A atividade e a política de microcrédito no Brasil: visões sobre a evolução e futuros desafios. São Paulo: USP.

McKernan, S. (2002). The impact of micro-credit programs on self-employment profits: do non-credit program aspects matter? The Review of Economics and Statistics, 84(1), 93-115. http://dx.doi.org/10.1162/003465302317331946

Menezes, N. A., Campos, G. S., \& Komatsu, B. K. (2014). A evolução da produtividade no Brasil. São Paulo.

MkNelly, B., \& Dunford, C. (1998). Impact of credit with education on mothers and their young children's nutrition: lower pra rural bank credit with education program in Ghana (Freedom from Hunger Research Paper, No. 4). Davis, CA: Freedom from Hunger.

MkNelly, B., \& Dunford, C. (1999). Impact of credit with education on mothers and their young children's nutrition. CRECER: credit with education program in Bolivia (Freedom from Hunger Research Paper, No. 5). Davis, CA: Freedom from Hunger.

Molineus, S.-A. (2015). Policy research discussion on microfinance. Wolrd Bank Group. Recuperado em 10 de janeiro de 2017, de http://pubdocs.worldbank.org/em/347661482181524371/ Sebastian-DECTalk-Microfinance.pdf

Morduch, J. (1998). Does microfinance really help the poor? New evidence from flagship programs in Bangladesh. Cambridge: Harvard University.

Neri, M. C. (2012). Microempresários nordestinos rurais e impactos do Agroamigo (221 p.). Rio de Janeiro: Elsevier. 
Oliveira, J. C. T., Almeida, A. T. C., \& Taques, F. H. (2015). Concentração e aderência dos recursos da carteira de financiamento do agroamigo: evidências para o nordeste brasileiro. Revista Economica do Nordeste, 46, 21-37.

Osmani, S. R., \& Mahmud, W. (2015). How does microcredit work? A review of the theories of microcredit (Working Paper, No. 35). Dhaka: Institute of Microfinance.

Pereira, E. L., \& Nascimento, J. S. (2014). Efeitos do Pronaf sobre a produção agrícola familiar dos municípios tocantinenses. Revista de Economia e Sociologia Rural, 52(1), 139-156.

Pitt, M. M., \& Khandker, S. (1998). The impact of group-based credit programs on poor households in Bangladesh: does the gender of participants matter? Journal of Political Economy, 106(5), 958-969. http://dx.doi.org/10.1086/250037

Quayes, S., \& Khalily, B. (2014). Efficiency of microfinance institutions in Bangladesh. Economic Bulletin, (3), 1512-1521.

Reed, L. R. (2015). Mapping pathways out of poverty. Washington.

Shah, T., Memon, I., Noonari, S., Ahmed, W., Mengal, A., Wagan, S., \& Sethar, A. (2015). Impact of microcredit on agricultural development in district mastung balochistan: a case study of Balochistan Rural Support Programme (BRSP). Journal of Poverty. Investment and Development, 9, 21-36.

Sharmeen, K., \& Chowdhury, S. (2013). agricultural growth and agricultural credit in the context of Bangladesh. Bangladesh Research Publications Journal, 8(2), 174-179.

Silva, S. P., \& Alves Filho, E. (2009). Impactos econômicos do Pronaf em territórios rurais: um estudo para o Médio Jequitinhonha - MG. Revista Econômica do Nordeste, 40(3), 481-498.

Sulemana, A., \& Adjei, S. A. (2015). Microfinance impact on agricultural production in developing countries: a study of the Pru District in Ghana. International Journal of Academic Research and Reflection, 3(3)

Wenner, M. (1995). Group credit: a means to improve information transfer and loan repayment performance. The Journal of Development Studies, 32(2), 263-281. http://dx.doi.org/10.1080/00220389508422414

Yunus, M. (2001). Microcrédito: a experiência do Grameen Bank. Rio de Janeiro: BNDES.

Yunus, M., \& Jolis, A. (2000). O banqueiro dos pobres. São Paulo: Ática.

Zeller, M., Diagne, A., \& Mataya, C. (1998). Market access by smallholder farmers in Malawi: implications for technology adoption, agricultural productivity and crop income. Agricultural Economics, 19(1-2), 219-229. http://dx.doi.org/10.1111/j.1574-0862.1998.tb00528.x

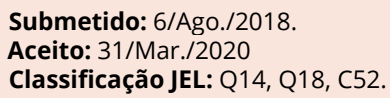

